\title{
Economics
}

\section{Gender, Education and Poverty in DR Congo: A Microeconomic Analysis Based on the Oaxaca-Blinder Decomposition}

\author{
Dieu-Merci Akonkwa Nyamuhirwa \\ Department of Socioeconomics, International Institute of Tropical Agriculture (IITA), Bukavu, DR Congo
}

Email address:

akonkwa.nyamuhirwa@ucbukavu.ac.cd

\section{To cite this article:}

Dieu-Merci Akonkwa Nyamuhirwa, Gender, Education and Poverty in DR Congo: A Microeconomic Analysis Based on Oaxaca-Blinder Decomposition. Economics. Vol. 8, No. 2, 2019, pp. 44-48. doi: 10.11648/j.eco.20190802.11

Received: January 9, 2019; Accepted: February 13, 2019; Published: April 29, 2019

\begin{abstract}
This paper analyzes gender, education and poverty in DRC through a Blinder-Oaxaca decomposition approach. The latter was needed in this study to judge the difference in level of consumption expenditure per adult equivalent per day depending on whether the household is headed by a man or a woman. Preliminary results based on the regression of the variable of interest (consumption expenditure per adult equivalent per day) on the endogenous variables considered (the age of the head of the household and his level of education) showed that age of household head is negatively influences the dependent variable when the head of household is a man and positively when it is a woman. It has also been found that educational attainment significantly influences the dependent variable at all levels of the education system considered in the female-headed household group. The decomposition showed that if female heads of household had the same endowments as men then the consumption expenditure per adult equivalent per day would decrease by approximately $\$ 0.0334$. In short, differences in staffing between male and female head of household are more beneficial to the household when the woman participates in the management of the household.
\end{abstract}

Keywords: Gender, Education, Poverty, Oaxaca-Blinder

\section{Introduction}

Very recently, it was found with non-supported economic performance over time, in 2050, only two countries (Nigeria and DRC) represent $40 \%$ of all people living in extreme poverty in the world [20]. In terms of the DR Congo, the situation is already alarming. Some authors estimate the level of poverty at $+/-70 \%[13,23-24]$ and $80 \%$ for others [14]. Despite this divergence of indicators, we nevertheless agree on the seriousness of the matter. However, several organizations, such as the Bill and Melinda Gates Foundation, believe that there is a need to invest enough in human capital in these two nations in order to reverse the trend [20]. The countries that understood it, those of East Asia, have very quickly developed effective education policies in order to reduce the knowledge and technology gap between them and other developed countries [22]. This attraction for investment in human capital is not recent. It is admitted that increasing schooling rates in a country goes hand in hand with higher GDP $[2-3,16]$. But if we have to invest, how should that be done?

In DR Congo, for example, it is since 2006 that the law on free primary education is included in the constitution, yet, currently, it is admitted that this policy has resulted in a failure in its implementation lack of a lack of realism [11-12]. Also, it should be noted that in DR Congo the job market remains largely dominated by men, which delays the return on investment in female human capital [13]. This reality is not specific to the country, it is observed in the world. Indeed, women around the world, in general, and in SubSaharan Africa, in particular, carry important responsibilities by doing unpaid work despite their human capital housework and caring for people at home and abroad. at the community level, which prevents them from being equal to men in the labor market and reduces the amount of time they can spend on personal care, social relations, politics and recreation $[4,5,7,19]$. It would be interesting to know what would be the difference in standard of living between male- 
headed and female-headed households. This is the fundamental question to which this study attempts to provide answers.

More concretely, this paper seeks to understand what would be the standard of living of households - estimated in terms of consumption expenditure per adult equivalent per day - in the DRC if the woman was head of household, on the one hand, and if she had the same endowment of human capital as their peer. For this, the Blinder-Oaxaca decomposition is used in order to highlight differences in living standards according to whether the head of household is a man or a woman. A priori, it is assumed that the differences in standard of living in DR Congo are due to differences in human capital endowments between male and female heads of households.

To be clear, the rest of this study is subdivided into three main sections. The first is an overview of the data description and presentation of variables (section 1), the second focuses on empirical methods (section 3) and the third section presents empirical results and their discussion. And finally a conclusion is presented.

\section{Data Description and Variables}

This section focuses on the description of data from the 2012 national database 123 used in this study as well as a brief presentation of the variables that will be introduced into the model.

\subsection{Data Description}

Data from 2012123 surveys are used for three main reasons. First, because representativeness is too great at the national level; secondly because the reliability of the data is great, especially since the data is collected by a team of people trained in advance and funded considerably but also because the control of data security exists to guarantee its validity. Surveys 123 cover the DR Congolese territory and are carried out by the National Institute of Statistics (INS) of DR Congo in collaboration with the Economic and Statistical Observatory of Sub-Saharan Africa (AFRISTAT) [9-10]. They are part of the assessment of the evolution of poverty and the monitoring of policies to reduce it. These surveys, in themselves, are three phases that provide information on three different aspects of economic and social life, namely employment (phase 1), the informal sector (phase 2) and household consumption (phase 3) [10]. Variables used from the 2012 database 123 presented in the following section. These are in all 5 variables.

\subsection{Variables}

Households are considered as a unit of analysis to assess the financial impact of education services. In this study, we retain the following variables:

\subsubsection{Sex of the Household Head}

The sex of the head of household ( $\operatorname{sexCM})$ : this is a qualitative variable to take into account the gender issue in the analysis. This variable will help to understand the difference in the incidence of education on poverty depending on whether the head of the household is a man or a woman. Two modalities are associated with it, it takes the value 1 when the head of the household is a man and 0 otherwise.

\subsubsection{Consumption Expenditure}

The total consumption expenditure variable is a quantitative variable that groups households' food and nonfood expenditures. This variable will be used as an indicator of poverty $[3,17-18]$ and therefore the study is placed in the "welfarist" current in that it uses an objective indicator based on household consumption expenditure to highlight their poverty status [15].

\subsubsection{Household Size Per Adult Equivalent}

Often analyzes considering the size of the household without distinction in terms of age among members leads to bias and correct this bias adult equivalent scale is generally used. The development of the equivalence scale presenting a difficult task, which explains the emergence of several methods for its construction ${ }^{1}$ [8]. In this paper, a pragmatic scale proposed by the OCDE (1992) is used. This consists in attributing to the reference adult (here the head of household) a weight equivalent to 1 , the other adults a weight of 0.7 and the children a weight of 0.5 . Thus, this is obtained by the following formula :

$$
\lambda=(1+\delta(a-1)+\theta c)^{\sigma}
$$

With $\lambda$ the parametric equivalence scale, $\mathrm{c}$ the number of children, has the number of adults, $\theta<1$ the needs of children compared to adults, $\delta$ provides information on the needs of additional adults compared to the first and $\sigma$ the parameter of relativity of scale. The latter measures the degree of economies of scale in terms of consumption, it generally between 0 and 1 [8]. For applied work, $\sigma$ is generally between 0.65 and 0.75 [8]. Thus for the present study, a value of $\sigma$ equal to 0.75 was retained. Note that there are no objective reasons for choosing this value.

\subsubsection{Level of Education}

Education level is a qualitative variable that accounts for the level of education of the head of the household. It takes into account three levels of the education system, namely the primary level, the secondary level and the higher level. It is clear that there is a positive relationship between educational attainment and consumption expenditure per adult equivalent. Also, it must be admitted that there is no prior relationship according to whether the household is headed by a woman or a man. In short, we can not predict the relationship.

\footnotetext{
1 For a detailed presentation of the various scales of equivalence proposed in the literature see Lorenzo G. (2006)
} 


\section{Empirical Method: Decomposition of Blinder-Oaxaca}

In his basic model, presented by Oaxaca, (1973) taken back by [15-21], the idea behind the decomposition of Oaxaca was to explain wage inequalities according to the characteristics of the subgroups. In this study, the goal is to find an explanation of the differences in consumption expenditure by adult equivalent depending on whether the household is headed by a man or a woman. [1].

Considering the two groups, male-headed households, group A, and female-headed households, group B, and the level of consumption expenditure per adult equivalent per day $\mathrm{Y}$, and other explanatory variables such as the level of education and the age of the head of the household. The question is then that it is the difference of the average consumption expenditure per adult equivalent between the two groups,

$$
R=E\left(Y_{A}\right)-E\left(Y_{B}\right)
$$

With E (Y) the mathematical expectation of the variable of interest. Since the variable of interest is a function of other variables, it can be estimated using the following regression model:

$$
Y_{l}=X_{l}^{\prime} \beta_{l}+\epsilon_{l}, E\left(\epsilon_{l}\right)=0 l \in(A, B)
$$

With $\mathrm{X}$ the vector containing the endogenous variables and the constant, $\beta$ containing the parameters to be estimated and the intercepts and $\varepsilon$ the error term, the difference of the means of consumption expenditure per adult equivalent per day given the two groups considered can then be written as follows:

$$
R=E\left(Y_{A}\right)-E\left(Y_{B}\right)=E\left(X_{A}\right)^{\prime} \beta_{A}-E\left(X_{B}\right)^{\prime} \beta_{B}
$$

Because

$$
E\left(Y_{l}\right)=E\left(X_{l}^{\prime} \beta_{l}+\epsilon_{l}\right)=E\left(X_{l}^{\prime} \beta_{l}\right)+E\left(\epsilon_{l}\right)=E\left(X_{l}^{\prime}\right) \beta_{l} \text { Où } E\left(\beta_{l}\right)=\beta_{l}
$$

by hypothesis.

To identify the contribution of groups in the predicted value gap, the previous gap equation can be rewritten as follows:

$$
R=\left\{E\left(X_{A}\right)-E\left(Y_{B}\right)\right\}^{\prime} \beta_{B}+E\left(X_{B}\right)^{\prime}\left(\beta_{A}-\beta_{B}\right)+\left\{E\left(X_{A}\right)-E\left(Y_{B}\right)\right\}^{\prime}\left(\beta_{A}-\beta_{B}\right)
$$

It should be noted that this decomposition is subdivided into three components:

$$
R=E+C+I
$$

The first component:

$$
E=\left\{E\left(X_{A}\right)-E\left(Y_{B}\right)\right\}^{\prime} \beta_{B}
$$

Is the part of the difference that is due to the difference between the groups in the endowments effect. The second component:

$$
C=E\left(X_{B}\right)^{\prime}\left(\beta_{A}-\beta_{B}\right)
$$

Measure the part of the difference due to the difference in the coefficients and the intercept (the coefficient effect). And the last component:

$$
I=\left\{E\left(X_{A}\right)-E\left(Y_{B}\right)\right\}^{\prime}\left(\beta_{A}-\beta_{B}\right)
$$

Is the interaction between the terms because the difference in endowments and coefficients exists simultaneously between the two groups.

As can be seen in the previous decomposition of the deviations, the different components are weighted by the coefficients of group B. The first two components can be interpreted in this way. The Endowments effect measures the expected change in average consumption expenditure per adult equivalent of group B if group B had the predicted level of group A.

Similarly, the effect coefficient measures the expected change in the average level of consumption expenditure per adult equivalent in group B if group B had the same coefficients as group A. Naturally this decomposition can also be written with weightings of the coefficients of group A.

\section{Empirical Results and Discussion}

After the presentation of the empirical method, this section presents the results obtained after analysis. The following point presents the preliminary results to the decomposition of Blinder-Oaxaca and the following the actual results of the decomposition.

\subsection{Preliminary Results of Oaxaca-Blinder Decomposition}

Generally before the decomposition of Blinder-Oaxaca, the regression is carried out within each of the groups considered. In the case of this study a first regression is made in the group of male-headed households and then in the group headed by women. The results are shown in the table below.

Although considering only two exogenous variables (the age of the head of household and his level of education) the models as specified are generally good, this results in the critical probabilities associated with the Fischer statistics. Considering the first endogenous variable, we find that the age of the head of household negatively influences the level of consumption expenditure per adult equivalent when the household is headed by a man and positively when the household is headed by a woman. However, it should be noted that the sign of the first model is not significant.

This result shows how the aging of the head of the household when the latter is headed by a man is an impoverishing factor of the household. An increase in age of one year leads to a decrease in consumption expenditure per adult equivalent per day of $\$ 0.003$. Considering the second 
exogenous variable, we find that the last two modalities considered for this variable positively and significantly influence the level of consumption expenditure per adult equivalent in the two groups under analysis. What is still interesting is that in the group of female-headed households even when this one has a primary level of education, the influence remains positive and significant even if the significance is not as high as in other modalities. Having done so, the results of the decomposition of the consumption expenditure differences per adult equivalent per day are presented in the following point.

Table 1. Preliminary Results of Decomposition.

\begin{tabular}{lll}
\hline \multirow{2}{*}{ VARIABLES } & $\mathbf{( 1 = \text { Male } )}$ & $\mathbf{( 2 = \text { female } )}$ \\
\cline { 2 - 3 } & $\mathbf{A E}$ consumption expenditure / day & AE consumption expenditure / day \\
\hline Age of the household head & -0.003 & $0.004^{* *}$ \\
& $(0.002)$ & $(0.002)$ \\
Level of education & & $0.148^{* *}$ \\
Primary & 0.041 & $(0.062)$ \\
Secondary & $(0.078)$ & $0.774^{* * *}$ \\
& $0.347^{* * *}$ & $(0.064)$ \\
Superior & $(0.070)$ & $3.055^{* * *}$ \\
& $2.075^{* * *}$ & $(0.135)$ \\
Constant & $(0.099)$ & $1.036^{* * *}$ \\
& $1.207^{* * *}$ & $(0.095)$ \\
Summary of models & $(0.099)$ & \\
observations & & 4,013 \\
R-squared & 17,441 & 0.131 \\
Prob $>$ F & 0.032 & 0.0000 \\
Root MSE & 0.0000 & 1.5702 \\
\hline
\end{tabular}

Standard errors in parentheses

$* * * \mathrm{p}<0.01, * * \mathrm{p}<0.05, * \mathrm{p}<0.1$

\subsection{Results of the Decomposition of Oaxaca-Blinder}

Considering the dependent variable, consumption expenditure per adult equivalent per day (converted into USD), the results of the Blinder-Oaxaca decomposition resulting from the analyzes whose methodological approach was presented in the previous section are presented in Table 2 below.

The first block in this table shows the average values of consumption expenditure per adult equivalent per day for both groups and the difference between the two. As can be seen, it appears that male-headed households have an average consumer spending per adult equivalent per day lower than that of households headed by women, namely $\$ 1.47$ and $\$ 1.57$, respectively. which translates into a difference of $-0.1035 \$$. These results demonstrate that, in relative terms, male-headed households are relatively poor compared to female-headed households on average. Which is contrary to the results [19].

The actual decomposition of the difference in consumption expenditure per adult equivalent per day between the two groups in three components already presented in the methodological section shows that if female household heads had the same endowments as the male heads of households, then the average consumption per adult equivalent per day of female-headed households would decrease by $\$ 0.0334$. This decrease of $\$ 0.0334$ in EA consumption expenditure per day shows that differences in educational investment, age of head of household and place of residence account for $33 \%$ of the difference in consumption expenditure per equivalent. adult per day between male-headed households and those headed by women.

The second component shows that consumption expenditure per adult equivalent per day of female-headed households would be $-.0652 \$$ if the male-headed households' coefficients were applied to the characteristics of female-headed households. This component accounts for $62.9 \%$ of the gap in consumer spending per adult equivalent between male-headed households and those headed by women. This shows that the effect of the coefficients largely explains the poverty differentials between male-headed and female-headed households. The third component presents the effect of the interaction.

Table 2. Results of the decomposition of Oaxaca-Blinder.

\begin{tabular}{|c|c|c|c|c|c|c|}
\hline \multirow{3}{*}{$\begin{array}{l}\text { Blinder-Oaxaca decomposition } \\
\text { Cons. Exp. EA/day }\end{array}$} & \multicolumn{3}{|l|}{ 1: Male } & \multirow{2}{*}{\multicolumn{3}{|c|}{ Number of obs. $=\mathbf{2 1 , 4 5 4}$}} \\
\hline & \multicolumn{3}{|l|}{ 2: Female } & & & \\
\hline & Coef. & Std. Err. & $\mathbf{Z}$ & $\mathbf{P}>\mathbf{Z}$ & \multicolumn{2}{|c|}{ [95\% Conf. Interval] } \\
\hline \multicolumn{7}{|l|}{ Differential } \\
\hline Prediction_1 & 1,4705 & 0,0242 & 60,7800 & 0,0000 & 1,4231 & 1,5179 \\
\hline Prediction_2 & 1,5740 & 0,0266 & 59,2100 & 0,0000 & 1,5219 & 1,6261 \\
\hline Difference & $-0,1035$ & 0,0359 & $-2,8800$ & 0,0040 & $-0,1739$ & $-0,0330$ \\
\hline \multicolumn{7}{|l|}{ Decomposition } \\
\hline Endowments & -.0334 & .0148 & -2.25 & 0.024 & -.0626 & -.0043 \\
\hline Coefficients & -.0652 & .0354 & -1.84 & 0.065 & -.1346 & .0041 \\
\hline Interaction & -.0048 & .0132 & -0.36 & 0.716 & -.0307 & .0211 \\
\hline
\end{tabular}




\section{Conclusion}

The purpose of this study was to analyze the microeconomic relationship that exists between education, gender and poverty in DR Congo. For this, she used the Blinder-Oaxaca decomposition to find explanations for the differences in consumption expenditure per adult equivalent per day between the group of male and female-headed households. The constructed model took into account the consumption expenditure per adult equivalent per day, on the one hand, and the educational level and the age of the head of the household, on the other side.

The analyzes revealed three things. First, at all levels of the education system considered, the woman's level of education as head of household significantly influences consumption expenditure per adult equivalent per day. Secondly, it has been found that female-headed households have relatively higher average per capita adult per day than men-headed households. This shows that female-headed households are doing better than those headed by men. And third, it turns out that if women heads of households had the same endowments in education or human capital and age then their average consumption per adult equivalent per day would decrease by $\$ 0.0334$. This shows that a good use of educational investment in women would be a better thing to fight against poverty.

\section{References}

[1] Doho, F., \& Boccanfuso, D. (2007). Does the Blinder-Oaxaca approach help identify the causes of poverty gaps in Guinea? University of SHERBROOKE.

[2] Arestoff, F., \& Sgard, J. (2012). Education, poverty, inequalities: which economic relations? CERISCOPE, 1-11. Barro, R. (1991). Economic growth in a crosssection of countries. The Quaterly Journal of Economics, 407-444.

[3] Blackden, M., \& Wodon, Q. (2006). Gender, Time Use, and Poverty in Sub-Saharan Africa. World Bank.

[4] Çagatay, N. (2001). Trade, gender and poverty. PNUD.

[5] Criade, C., \& Adèle, B. (2013). The determinants of the gender pay gap in the US: a linear and quantile approach. Laval University.

[6] Dong, X.-Y., \& An, X. (2012). Gender Patterns and Value of Unpaid Work. UNRISD.
[7] FAO. (2006). Scale of equivalence subjective methods. EASYPOL module 033.

[8] INS, \& Min. Plan. (2005). Global report survey 123-2005. INS.

[9] INS, \& Min. Plan. (2014). Global report survey 123-2012. INS.

[10] ISU. (2010). Receuil global data on education. UNESCO. ISU. (2012). Opportunité perdues: impact du refoublement et du départ prématuré de l'école. INESCO.

[11] Kamala, K., Muhinduka, D.-K., \& Mahuhira, C. (2017). Education, health and poverty in the Democratic Republic of Congo, 2005-2012. Economic and Social Papers, 151-173.

[12] Kodila, O. (2010). Poverty in the Democratic Republic of Congo: A quick inventory. Congo Economic Review, 1-28.

[13] Lubrano, M. (2008). Introduction to econometrics of poverty measures. GREQAM, 32.

[14] Mankiw, N., Romer, D., \& Weil, D. (1992). A contribution to the empirics of endogenous growth. The Quaterly Journal of Economic, 501-526.

[15] Marivoet, W., \& Keje, H. (2011). Deepen the geographical profiling of poverty in the DRC: The introduction of composite indexes on the basis of assets. Univesity of Antwerp.

[16] Moummi, A. (2010). Analysis of poverty in the Democratic Republic of Congo. Working paper Series, No. 112, August, ADB.

[17] Okojie, C. (2002). Gender and Education as Determinants of Household Poverty in Nigeria. United Nations University.

[18] Olwoseye, A. (2018, 10 22). www.premiumtimesng.com. Retrieved from www.premiumtimesng.com/news/headlines/284195bi...human-capital-as-way-out-of-poverty.

[19] Ospino, C., Vasquez, P., \& Narváez, N. (2009). OaxacaBlinder wage decomposition: methods, critiques and applicatiOns. a literature review. GRANECO.

[20] Stiglitz, J. (2002). The great disillusionment. Norton: Arthème Fayard Bookstore.

[21] Tshiebue, N. (2017). Rural development: realities, challenges and courses of action. African notebook.

[22] WFP. (2014). In-Depth Analysis of Food Security and Vulnerability (CFSVA). Rome: World Food Program. 